\title{
Effects of Dietary Cholesterol on Plasma Lipoproteins in Smith-Lemli-Opitz Syndrome
}

\author{
LOUISE S. MERKENS, WILLIAM E. CONNOR, LEESA M. LINCK, DON S. LIN, \\ DONNA P. FLAVELL, AND ROBERT D. STEINER
}

\begin{abstract}
Department of Pediatrics [L.S.M., R.D.S.]; Division of Endocrinology, Metabolism and Nutrition [W.E.C., D.S.L., D.P.F.], Department of Medicine, OR Health \& Science University, Portland, OR 97239;

Department of Genetics [L.M.L.], Kaiser Permanente Northwest, Portland,OR 97227; and Department of Molecular and Medical Genetics [L.M.L., R.D.S.], Child Development and Rehabilitation Center, Doernbecher Children's Hospital, OR Health \& Science University, Portland, OR 97239
\end{abstract}

\begin{abstract}
Smith-Lemli-Opitz syndrome is a condition of impaired cholesterol synthesis that is caused by mutations in DHCR7 encoding 7-dehydrocholesterol- $\Delta^{7}$ reductase. Birth defects and mental retardation are characteristic. Deficient plasma and tissue cholesterol and excess cholesterol precursors 7 and 8 dehydrocholesterol (7DHC and $8 \mathrm{DHC}$ ) contribute to the pathogenesis. Cholesterol is transported to tissues via lipoproteins. We measured the effect of dietary cholesterol (egg yolk) on plasma lipoproteins to evaluate this potential treatment. We used the enzymatic method to measure total sterols in lipoproteins $(n=12)$ and plasma $(n=16)$. In addition, we analyzed individual plasma sterols by a gas chromatographic method. Samples were evaluated after 3 wk of a cholesterol-free diet and after 6-19 mo of dietary cholesterol. We also analyzed the distribution of sterols in lipoproteins and the apolipoprotein $\mathrm{E}$ genotype. Dietary cholesterol significantly increased the total sterols in plasma (2.22 \pm 0.13 to $3.10 \pm 0.22$; mean \pm SEM; $p<0.002$ ), in $\operatorname{LDL}(0.98 \pm 0.13$ to $1.52 \pm 0.17 \mathrm{mM})$, and in $\operatorname{HDL}(0.72 \pm 0.04$ to $0.92 \pm 0.07)$. Plasma cholesterol increased $(1.78 \pm 0.16$ to
\end{abstract}

\section{ABSTRACT}

$2.67 \pm 0.25 \mathrm{mM} ; p<0.007)$ and plasma 7DHC decreased in 10 children, but the mean decrease was not significant. The distribution of individual sterols in each lipoprotein fraction was similar to the distribution in plasma. The baseline cholesterol and the response to dietary cholesterol was the same in children with $3 / 3$ and $3 / 4$ apolipoprotein E genotypes. Dietary cholesterol increased total sterols in plasma, LDL, and HDL in children with Smith-Lemli-Opitz syndrome. These favorable increases in the lipoproteins are potentially therapeutic for this condition. (Pediatr Res 56: 726-732, 2004)

apoE, apolipoprotein $\mathrm{E}$

\section{Abbreviations}

DHCR7, 7-dehydrocholesterol $\Delta^{7}$-reductase

HMG, hepatic hydroxymethyl glutaryl

SLOS, Smith-Lemli-Opitz syndrome

7DHC, 7-dehydrocholesterol

8DHC, 8-dehydrocholesterol
The Smith-Lemli-Opitz syndrome (SLOS) is an autosomal recessive condition with multiple malformations and mental retardation (OMIM \#270400). SLOS is caused by mutations in the gene encoding the final enzyme in the cholesterol biosynthetic pathway 7-dehydrocholesterol $\Delta^{7}$-reductase (DHCR7;

Received January 20, 2004; accepted July 7, 2004.

Correspondence: Robert D. Steiner, M.D., Department of Pediatrics \& Molecular and Medical Genetics, Child Development and Rehabilitation Center, Doernbecher Children's Hospital, OR Health \& Science University, CDRC-F, 707 SW Gaines, Portland, OR 97239; e-mail: SteinerR@ohsu.edu

Supported by grants from the National Heart, Lung, and Blood Institute (PHS HL64618 and HL-073980); National Center for Research Resources (PHS 5 M01 RR000334 and PHS 3 M01 RR003344-33S3); National Institute for Child Health and Human Development, OR Child Health Research Center (PHS 5P30 HD33703-04); the American Academy of Pediatrics Section on Genetics and Birth Defects; the Collins Foundation; and the Smith-Lemli-Opitz Advocacy and Exchange. R.D.S. is a Clinical Associate Physician Investigator of the Oregon Health \& Science University General Clinical Research Center.

DOI: 10.1203/01.PDR.0000141522.14177.4F
E.C 1.3.1.21). Although the syndrome was initially described in 1964 (1), it was not until 30 y later that deficiency of a cholesterol biosynthetic enzyme was identified as the cause of the syndrome (2-4). The identification and cloning of the gene defective in SLOS, DHCR7, were reported in 1998 (5-7). Currently, $>80$ different mutations in $D H C R 7$ have been found to be associated with $\operatorname{SLOS}(8,9)$.

SLOS is characterized clinically by microcephaly, cleft palate, dysmorphic facies, limb abnormalities (especially syndactyly of toes 2 and 3), genital anomalies, endocrine malfunction, cataracts, malformation in the heart and kidney, mental retardation, feeding difficulties, and growth retardation (10). Clinical features are variable in severity, presumably reflecting the specific causative mutations and the extent of the decrease in enzyme activity. Some mildly affected patients exhibit only a few of the described features.

The biochemical consequences of the enzyme deficiency include abnormally low or low-normal cholesterol concentra- 
tions along with accumulation of the precursor that is the substrate of DHCR7, 7-dehydrocholesterol (7DHC), and its derivative 8 -dehydrocholesterol (8DHC). Treatment is sought to correct the biochemical imbalance and improve physical and psychomotor development.

Several studies have been conducted to evaluate the effects of supplemental and dietary cholesterol as a potential treatment for this condition (11-19). These studies evaluated the effect of supplemental and/or dietary cholesterol on plasma sterol (cholesterol, 7DHC, 8DHC) concentrations. In the current study, in addition to measuring plasma sterols, we analyzed lipoproteins (LDL, HDL, VLDL, and triglyceride) to test the hypothesis that dietary cholesterol will increase total sterols in LDL. A second objective was to determine the distribution of cholesterol, 7DHC, and 8DHC in lipoproteins because this has not been reported previously. We measured lipoprotein sterols at baseline (after $3 \mathrm{wk}$ of an essentially cholesterol-free diet) and after 6-19 mo of dietary cholesterol primarily from egg yolk. A third objective was to determine whether apolipoprotein $\mathrm{E}$ (apoE) genotype affects the response to dietary cholesterol.

\section{METHODS}

Subjects and study design. Sixteen children with SLOS were enrolled; two of the children were siblings. We have previously reported data on plasma sterol levels, sterol synthesis, urinary mevalonate, and DNA mutations in as many as 14 of these children (19-22), but we have not previously reported lipoprotein data. All study children had clinical features of SLOS and elevated 7DHC and 8DHC plasma concentrations diagnostic of SLOS. The children (Table 1) were admitted to the Oregon Health \& Science University General Clinical Research Center for 1-wk periods. Parents were instructed to feed their child an essentially cholesterol-free diet (baseline diet) at home for 3-4 wk before the first admission to establish baseline conditions. The cholesterol content of these diets ranged from 0.4 to $3.3 \mathrm{mg}$ cholesterol $\cdot \mathrm{kg}^{-1} \cdot \mathrm{d}^{-1}$; one child was breast fed and consumed $14 \mathrm{mg}$ cholesterol $\cdot \mathrm{kg}^{-1} \cdot \mathrm{d}^{-1}$ contained in breast milk. The baseline diet period was repeated when the initial study was unsuccessful as a result of illness, nonadherence to diet, difficulties with sample collection, or other reason. During these admissions, the baseline diet was continued under metabolic ward conditions. On discharge, children were prescribed dietary cholesterol as egg yolk and/or butter fat. In a few cases, crystalline cholesterol in oil or emulsion was prescribed. For all other admissions, the children continued to receive cholesterol. Children returned every 3-12 mo for monitoring. Blood samples were evaluated during the last week of the baseline diet and after 6-19 mo of dietary cholesterol.

Details of the diets are described in previous reports $(18,19)$. In summary, children aged 0-6 mo were fed one half egg yolk/d; children aged 6-12 mo were fed $1 \mathrm{egg}$ yolk/d; and children aged 12 mo or older were fed 1.5 to $2 \mathrm{egg}$ yolks/d. On the basis of an estimate of $210 \mathrm{mg}$ of cholesterol per egg yolk, the children received $\sim 18-60 \mathrm{mg} \cdot \mathrm{kg}^{-1} \cdot \mathrm{d}^{-1}$ of cholesterol. Eggs were hardboiled, and the yolks removed and mixed with formula, breast milk, or solid food, according to the child's regular diet. At times, egg yolk was cooked in formula or milk. Egg yolks were also provided as powdered egg yolk (subjects 5 and 9) or as whole eggs (in subject 8 for $46 \%$ of the duration of the dietary cholesterol period). Powdered egg yolk was stored at $4^{\circ} \mathrm{C}$ to prevent oxidation of its cholesterol. Six children received butter fat, heavy cream, crystalline cholesterol in soybean oil (16), or crystalline cholesterol in an aqueous suspension (23) instead of egg yolk during some or all of the supplemental cholesterol period. Table 2 describes the source and duration of the supplemental cholesterol (other than egg yolk) for these children. Feeding difficulties are common in SLOS, and seven of the 16 children in our study required tube feeding. The same dietary protocols were used for children

Table 1. Baseline characteristics and plasma sterol concentrations of children with SLOS

\begin{tabular}{|c|c|c|c|c|c|c|}
\hline $\begin{array}{l}\text { Children } \\
\text { (gender) }\end{array}$ & $\begin{array}{c}\text { Age at } \\
\text { baseline } \\
\text { (y) }\end{array}$ & $\begin{array}{c}\text { Cholesterol* } \\
(\mathrm{mmol} / \mathrm{L} \ddagger)\end{array}$ & $\begin{array}{c}8 \mathrm{DHC}^{*} \\
(\mathrm{mmol} / \mathrm{L})\end{array}$ & $\begin{array}{c}\text { 7DHC* } \\
(\mathrm{mmol} / \mathrm{L})\end{array}$ & ApoE & $\begin{array}{c}\text { Duration } \\
(\operatorname{mos})\end{array}$ \\
\hline $1(\mathrm{~F})$ & 3.5 & 2.83 & 0.06 & 0.21 & $3 / 3$ & 17.5 \\
\hline $2(\mathrm{M})$ & 12.4 & 2.70 & 0.31 & 0.35 & $3 / 4$ & 14.2 \\
\hline $3(\mathrm{~F})$ & 3.0 & 2.61 & 0.06 & 0.06 & $3 / 3$ & 6.3 \\
\hline $4(\mathrm{M})$ & 2.0 & 2.45 & 0.07 & 0.12 & $3 / 3$ & 6.6 \\
\hline $5(\mathrm{M})$ & 0.1 & 2.13 & 0.26 & 0.33 & $2 / 4$ & 10.4 \\
\hline $6(\mathrm{~F})$ & 1.9 & 2.08 & 0.12 & 0.08 & NA§ & 6.2 \\
\hline $7(\mathrm{~F})$ & 12.0 & 2.02 & 0.15 & 0.13 & $3 / 3$ & 19.4 \\
\hline $8(\mathrm{M})$ & 0.1 & 1.95 & 0.12 & 0.24 & $3 / 3$ & 13.5 \\
\hline $9(\mathrm{~F})$ & 3.0 & 1.54 & 0.25 & 0.30 & $2 / 3$ & 10.6 \\
\hline $10(\mathrm{~F})$ & 5.2 & 1.49 & 0.13 & 0.10 & $3 / 3$ & 6.8 \\
\hline $11(\mathrm{M})$ & 0.5 & 1.37 & 0.20 & 0.28 & $3 / 4$ & 10.4 \\
\hline $12(\mathrm{~F})$ & 8.7 & 1.28 & 0.23 & 0.31 & $3 / 3$ & 19.4 \\
\hline $13(\mathrm{~F})$ & 2.7 & 1.21 & 0.36 & 0.25 & $3 / 4$ & 6.0 \\
\hline $14(\mathrm{M})$ & 13.6 & 1.03 & 0.24 & 0.33 & $3 / 3$ & 19.4 \\
\hline $15(\mathrm{~F})$ & 7.9 & 1.03 & 0.31 & 0.36 & $3 / 3$ & 9.7 \\
\hline $16(\mathrm{~F})$ & 0.2 & 0.80 & 0.25 & 0.26 & $3 / 3$ & 8.3 \\
\hline
\end{tabular}

* Plasma concentration at the baseline diet (essentially cholesterol-free) by gas chromatography.

$\dagger$ Duration of dietary cholesterol.

$\ddagger \mathrm{mmol} / \mathrm{L} \times 38.67=\mathrm{mg} / \mathrm{dL}$.

$\S$ Genomic DNA not available. 
Table 2. Details of supplemental and dietary cholesterol for children with alternative sources of cholesterol other than egg yolk

\begin{tabular}{clccc}
\hline Subject & \multicolumn{1}{c}{ Alternative sources } & Alternative/total* & Cholesterol intake & $\begin{array}{c}\text { Cholesterol source at study } \\
\text { conclusion }\end{array}$ \\
\hline & & $(\mathrm{mo} / \mathrm{mo})$ & $\left(\mathrm{mg} \cdot \mathrm{kg}^{-1} \cdot \mathrm{d}^{-1}\right)$ & \\
1 & Crystalline cholesterol in oil $(16)$ & $4.0 / 17.5$ & 75.5 & Aqueous crystalline cholesterol \\
2 & Aqueous crystalline cholesterol $\dagger$ & $14.2 / 14.2$ & 11.8 & Aqueous crystalline cholesterol \\
3 & Heavy cream or crystalline cholesterol in oil (16) & $1.8 / 6.3$ & 42.2 & Crystalline cholesterol in oil \\
6 & Aqueous crystalline cholesterol $\dagger$ & $6.2 / 6.2$ & 118.4 & Aqueous crystalline cholesterol \\
13 & Butter fat & $3.6 / 6.0$ & 40.8 & Egg yolk \\
16 & Aqueous crystalline cholesterol $\dagger$ & $4.5 / 8.3$ & 169.7 & Aqueous crystalline cholesterol \\
\hline
\end{tabular}

* Months of alternative cholesterol/duration of the total period of supplemental cholesterol.

$\dagger$ Suspended in Ora-Plus (23).

who were tube fed or orally fed. These studies were approved by the Oregon Health \& Science University (Portland, OR) Institutional Review Board; the parents gave informed consent for the participation of their child.

Lipoprotein and plasma sterol analysis. Total sterols in each lipoprotein fraction and in plasma as well as plasma triglycerides were measured by the standard clinical method (enzymatic method) with a Hitachi 704 Chemistry Analyzer, in compliance with the standardization and surveillance programs of the Centers for Disease Control and Prevention Laboratory (Atlanta, GA) $(24,25)$. This enzymatic method uses cholesterol esterase and cholesterol oxidase and overestimates plasma cholesterol concentrations from children with SLOS because dehydrocholesterols are substrates for cholesterol oxidase and contribute to the resulting value (26). In plasma, the sum of the sterols (measured individually by gas chromatographic method) was similar to the total sterols (measured by enzymatic method) at baseline and after dietary cholesterol $\left(R^{2}=\right.$ 0.98 ). Therefore, we assumed for subsequent analyses by the enzymatic method that each value represented "total sterols," that is, cholesterol, 7DHC, and 8DHC.

We measured the concentrations of individual sterols (cholesterol, 7DHC, and 8DHC) in each lipoprotein fraction (LDL, HDL, and VLDL) after separation by ultracentrifugation (24) $(n=2)$. This ultracentrifugation step requires more blood than is routinely obtained in these small children, so we were able to do this only with two children. Both children were receiving dietary cholesterol at the time of measurement. In all of the children, we measured the concentrations of individual sterols in plasma. These individual plasma sterol concentrations were measured by capillary-column gas chromatography with a CP-Wax 57 column (25 M, 0.32 mm ID; Chrompack Co., Raritan, NJ) $(5,20)$. Internal standard (5 $\alpha$-cholestane) and an authentic standard of the cholesterol were used for calibration. In the two children, the distribution of individual sterols in each lipoprotein was the same as the distribution in plasma. Assuming that this was the case for all of the children, we calculated the concentrations of cholesterol, 7DHC, and 8DHC in each lipoprotein fraction. For example, the concentration of cholesterol in LDL equals the ratio of cholesterol to total sterols in plasma sample (gas chromatographic method) multiplied by the total sterol concentration in LDL (enzymatic method).
Data are expressed as means \pm SEM. Statistical analysis of differences between means was determined using a two-tailed $t$ test for paired samples.

ApoE genotyping. The apoE gene has three alleles, $\epsilon 2, \epsilon 3$, and $\epsilon 4$, coding for the three major isoforms (E2, E3, and E4) of this protein. The alleles were identified by PCR amplification of nucleotides 2823-3093 followed by restriction endonuclease digestion with HhaI. The six possible genotypes were determined from the sizes of the DNA fragments (27).

\section{RESULTS}

Effect of dietary cholesterol on lipoproteins and total sterols. By the enzymatic method, we measured total sterols in plasma (16 children) and total sterols in each lipoprotein fraction (12 children). Measurements that were taken at baseline (after $3 \mathrm{wk}$ of an essentially cholesterol-free diet) were compared with measurements after 6-19 mo of dietary cholesterol. The total sterols in plasma increased from 2.22 to 3.10 $\mathrm{mM}(p<0.002$; Table 3). Six children received alternative sources of cholesterol instead of egg yolk during some or all of the supplemental cholesterol period. The total sterols in this subgroup increased from $2.38 \pm 0.28$ to $3.26 \pm 0.28 \mathrm{mM}$. Total sterols in LDL (enzymatic method) increased significantly (from 0.98 to $1.52 \mathrm{mM} ; p<0.02$ ) in parallel with the increase in total plasma sterols. HDL increased similarly from 0.72 to $0.92 \mathrm{mM}(p<0.03)$. There were no changes in total sterols in VLDL (0.49 to $0.58 \mathrm{mM} ; p=0.48)$ or in plasma triglyceride concentrations ( 1.11 to $1.24 \mathrm{mM} ; p=0.49$ ) in response to the dietary cholesterol. Under normal conditions, changes in dietary cholesterol do not affect VLDL cholesterol or plasma triglyceride concentrations (28). In children 5-9 y of age, the normal triglyceride concentration in fasting plasma ranges from 31 to $104 \mathrm{mg} / \mathrm{dL}$ (29). Our values for triglycerides are slightly higher, likely because fasting samples could not be obtained from infants.

Effect of dietary cholesterol on plasma concentrations of cholesterol, $7 \mathbf{D H C}$, and $\mathbf{8 D H C}$. To determine whether the increase in total sterols resulted specifically from an increase in the cholesterol component of plasma, we measured plasma cholesterol, 7DHC, and 8DHC concentrations in 16 SLOS children at baseline (after $3 \mathrm{wk}$ of essentially cholesterol-free diet) and after 6-19 mo of dietary cholesterol. Dietary choles- 
Table 3. Changes in total sterols in plasma, VLDL, LDL, and $H D L$

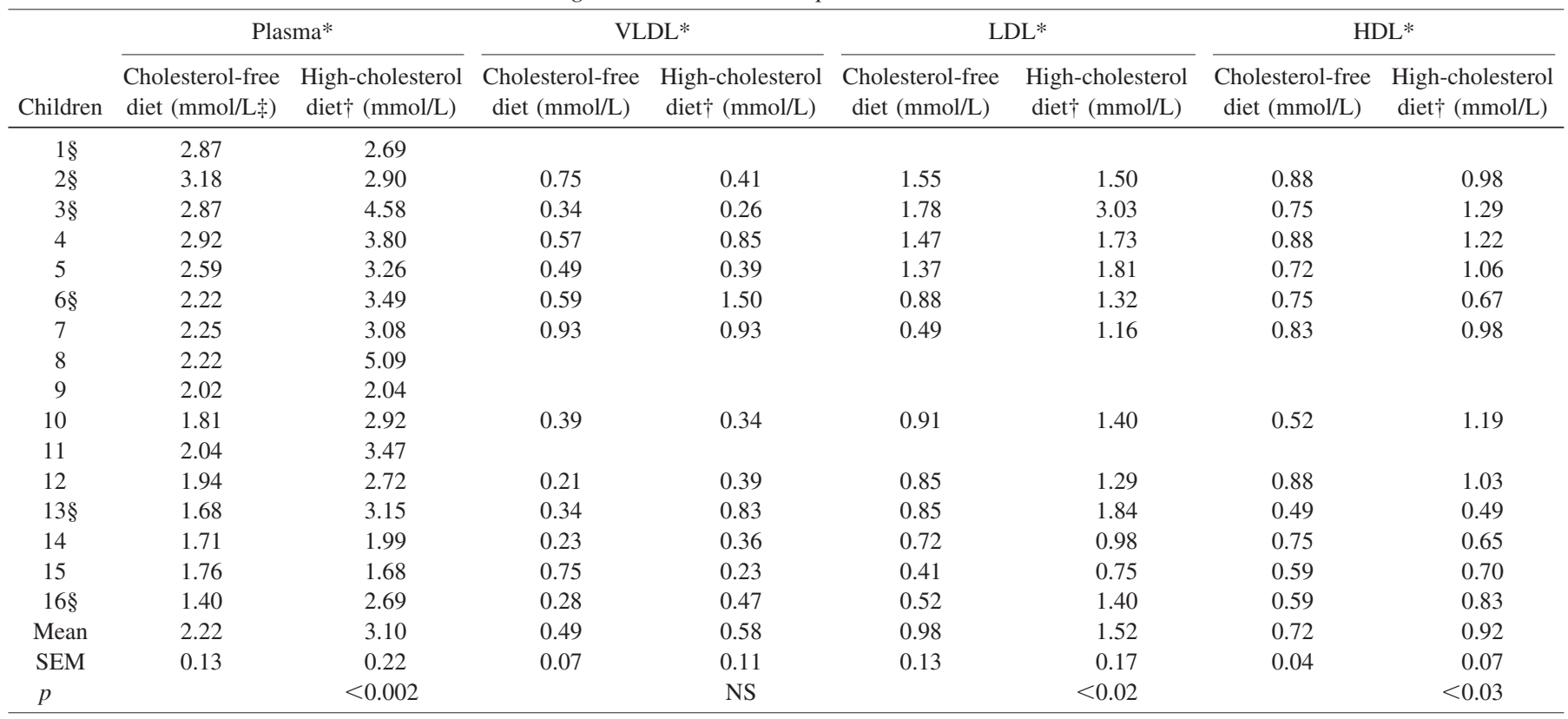

* Concentrations of total sterols in plasma and lipoprotein fraction (enzymatic method).

$\dagger$ After 6-19 months of dietary cholesterol.

$\ddagger \mathrm{mmol} / \mathrm{L} \times 38.67=\mathrm{mg} / \mathrm{dL}$.

$\S$ Receiving alternative sources of cholesterol during all or part of the 6- to 19-month period.

terol raised plasma cholesterol from 1.78 to $2.67 \mathrm{mM}(p<$ 0.007; Table 4). Not only did the concentration of plasma cholesterol increase, but also the ratio of cholesterol relative to the sum of all sterols increased from 0.79 to 0.84 . Dietary cholesterol did not significantly decrease the mean plasma 7DHC (Table 4) or 8DHC (0.23-0.21 mM and 0.19-0.20 mM, respectively).
At baseline, there was no correlation between the concentrations of cholesterol and 7DHC. After dietary cholesterol, however, there was a significant negative correlation $\left(R^{2}=\right.$ $0.62, p<0.01$; Fig. 1). Children who responded to the dietary cholesterol with the greatest increase in plasma cholesterol concentrations tended to obtain the lowest 7DHC concentrations.

Table 4. Individual sterol changes in plasma after dietary cholesterol

\begin{tabular}{|c|c|c|c|c|c|c|}
\hline \multirow[b]{2}{*}{ Subject } & \multicolumn{3}{|c|}{ Cholesterol* } & \multicolumn{3}{|c|}{ 7DHC* } \\
\hline & $\begin{array}{l}\text { Cholesterol-free } \\
\text { diet }(\mathrm{mmol} / \mathrm{L} \ddagger)\end{array}$ & 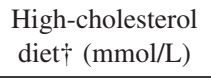 & $\begin{array}{c}\text { Change } \\
(\mathrm{mmol} / \mathrm{L})\end{array}$ & $\begin{array}{c}\text { Cholesterol-free } \\
\text { diet }(\mathrm{mmol} / \mathrm{L})\end{array}$ & $\begin{array}{c}\text { High-cholesterol } \\
\text { diet } \dagger(\mathrm{mmol} / \mathrm{L})\end{array}$ & $\begin{array}{c}\text { Change } \\
(\mathrm{mmol} / \mathrm{L})\end{array}$ \\
\hline $1 \S$ & 2.83 & 2.72 & -0.11 & 0.21 & 0.08 & -0.12 \\
\hline $2 \S$ & 2.70 & 2.40 & -0.30 & 0.35 & 0.27 & -0.09 \\
\hline $3 \S$ & 2.61 & 4.43 & 1.82 & 0.06 & 0.04 & -0.02 \\
\hline 4 & 2.45 & 3.52 & 1.06 & 0.12 & 0.10 & -0.02 \\
\hline 5 & 2.13 & 2.95 & 0.82 & 0.33 & 0.16 & -0.17 \\
\hline $6 \S$ & 2.08 & 3.51 & 1.44 & 0.08 & 0.02 & -0.06 \\
\hline 7 & 2.02 & 2.77 & 0.75 & 0.13 & 0.22 & 0.08 \\
\hline 8 & 1.95 & 4.62 & 2.67 & 0.24 & 0.08 & -0.16 \\
\hline 9 & 1.54 & 1.30 & -0.24 & 0.30 & 0.46 & 0.16 \\
\hline 10 & 1.49 & 2.58 & 1.09 & 0.10 & 0.14 & 0.04 \\
\hline 11 & 1.37 & 2.82 & 1.46 & 0.28 & 0.26 & -0.02 \\
\hline 12 & 1.28 & 2.09 & 0.81 & 0.31 & 0.32 & 0.01 \\
\hline $13 \S$ & 1.21 & 2.28 & 1.07 & 0.25 & 0.43 & 0.19 \\
\hline 14 & 1.03 & 1.35 & 0.32 & 0.33 & 0.34 & 0.02 \\
\hline 15 & 1.03 & 1.01 & -0.02 & 0.36 & 0.32 & -0.04 \\
\hline $16 \S$ & 0.80 & 2.33 & 1.53 & 0.26 & 0.15 & -0.11 \\
\hline Mean \pm & 1.78 & 2.67 & $0.89 \|$ & 0.23 & 0.21 & $-0.02 \|$ \\
\hline SEM & 0.16 & 0.25 & & 0.03 & 0.03 & \\
\hline$p$ & & $<0.007$ & & & NS & \\
\hline
\end{tabular}

* Concentration in plasma as measured by gas chromatography.

$\dagger$ After 6 to 19 months of dietary cholesterol.

$\ddagger \mathrm{mmol} / \mathrm{L} \times 38.67=\mathrm{mg} / \mathrm{dL}$

$\S$ Receiving alternative sources of cholesterol during all or part of the 6- to 19-month period.

|| Plasma cholesterol increased 57\%, and the plasma 7DHC decreased $8.8 \%$. 


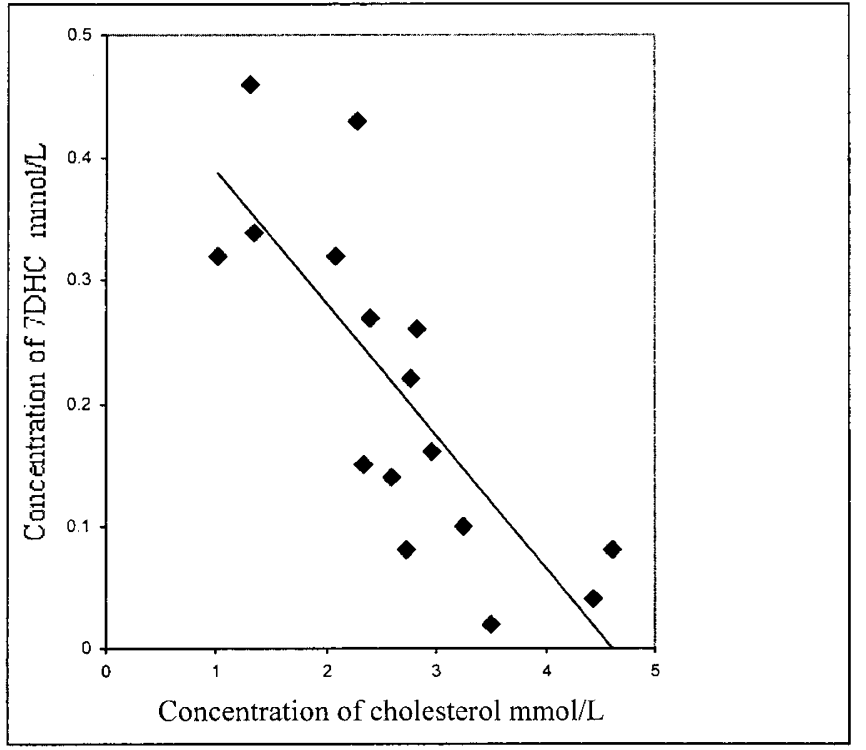

Figure 1. After 6-19 mo of dietary cholesterol, the concentrations of cholesterol and 7DHC in the 16 children have a significant negative correlation $\left(R^{2}=0.62, p<0.01\right)$.

Distribution of sterols within each lipoprotein fraction. The increase in total sterols in LDL and HDL could result from an increase either in cholesterol or in the precursor sterols 7DHC or $8 \mathrm{DHC}$. The plasma samples from two children had an adequate volume to separate the VLDL, LDL, and HDL by ultracentrifugation. We then measured the individual sterol concentrations (cholesterol, 7DHC, and 8DHC) by gas chromatographic method in each fraction. We compared the distribution of individual sterols in each lipoprotein with the distribution of individual sterols measured in plasma (Fig. 2). The concentrations of total sterols in each of these two children (subjects 7 and 9) were different from one another (2.43 and $1.24 \mathrm{mM}$, respectively). In addition, the distribution of cholesterol relative to the total sterols in plasma was different in these two children (90 and 70\%, respectively). For each child individually, however, the distribution of cholesterol, 7DHC, and $8 \mathrm{DHC}$ (relative to total sterols) in each lipoprotein fraction was the same as the distribution in plasma (Fig. 2). Assuming that this is true for all cases, we calculated the concentration of cholesterol in LDL and HDL for each child $(n=12)$. Results showed that LDL cholesterol increased from $0.73 \pm 00.13$ to $1.31 \pm 0.18 \mathrm{mM}(p<0.02)$ and HDL cholesterol increased from $0.57 \pm 0.05$ to $0.79 \pm 0.08 \mathrm{mM}(p<0.03)$. The concentrations of 7DHC in LDL $(0.10 \mathrm{mM}$ and $0.11 \mathrm{mM})$ or 8DHC in LDL (0.09 and $0.10 \mathrm{mM}$ ) did not change.

Lack of effect of apoE genotype on plasma cholesterol and on efficacy of dietary cholesterol. Plasma sterols in SLOS children varied widely at baseline and after dietary cholesterol. Of the three isoforms of apoE, the E4 isoform is associated with increased concentration of plasma cholesterol (30). We determined whether apoE genotype could account for some of this variability. Three of the SLOS children had the 3/4 apoE genotype, whereas nine had the $3 / 3$ genotype. Plasma cholesterol concentrations, however, were similar in SLOS children with either genotype at baseline $(1.74$ versus $1.80 \mathrm{mM} ; p=$

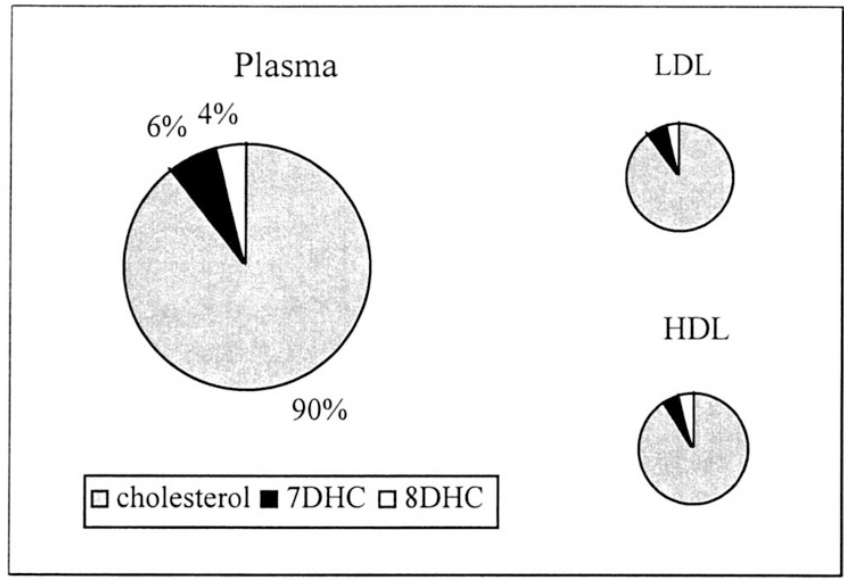

A

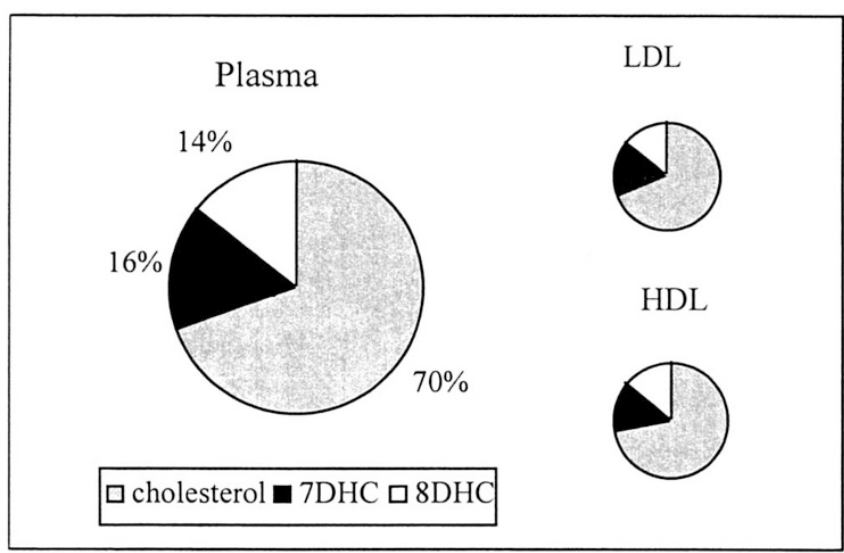

B

Figure 2. The distribution of cholesterol, 7DHC, and 8DHC (as measured by gas chromatography) in each lipoprotein fraction is similar to the distribution in plasma as measured in two children [subject $7(A)$ and subject $9(B)$ ]. Light gray is the percentage of cholesterol, black is the percentage of $7 \mathrm{DHC}$, and white is the percentage of $8 \mathrm{DHC}$. Samples were obtained after 38 mo (subject 7) and 60 mo (subject 9) of dietary cholesterol. In these samples, the total sterols in plasma for subject 7 is $2.43 \mathrm{mM}$, and the total sterols in plasma for subject 9 is $1.24 \mathrm{mM}$.

$0.90)$ and after $6-19$ mo of dietary cholesterol (2.62 versus $2.81 \mathrm{mM} ; p=0.80 ; 3 / 4$ and $3 / 3$, respectively).

\section{DISCUSSION}

Cholesterol deficiency is characteristic of SLOS and may be a major contributor to the characteristic clinical features. Cholesterol is an essential component of cell membranes and nervous system neurons and myelin, as well as serving as the substrate for important biologic compounds, including bile acids and steroid hormones. Recently, cholesterol was shown to be an essential component of the lipid rafts involved in intracellular trafficking of proteins and lipids (31) and cell surface signaling proteins (32). In addition, cholesterol has been shown to promote CNS synaptogenesis (33). Cholesterol also plays a critical role during fetal development. The cholesterol molecule is a covalently bound component of active hedgehog proteins, a family of embryonic signaling proteins 
(34). Cholesterol deficiency could alter the function of the hedgehog signaling pathway.

In SLOS, some of the pathologic characteristics may also be due to accumulation of cholesterol precursors. For example, accumulation of 7DHC in the brain has been associated with impaired learning in rats (35). 7DHC has also been shown to be teratogenic in rat embryos (36). Therefore, treatment for SLOS that normalizes plasma and tissue cholesterol levels while decreasing accumulation of potentially toxic cholesterol intermediates and metabolites is sought. Dietary cholesterol has been considered a potential treatment.

Lipoproteins are essential for transport of dietary cholesterol from the intestines to the other tissues of the body as well as for cellular uptake of cholesterol. We measured total sterols in each lipoprotein fraction in 12 children. The total sterols significantly increased in LDL and HDL in response to dietary cholesterol. The ratios of noncholesterol sterols to cholesterol in serum do not always predict the ratios in the different lipoproteins (37). Therefore, in two children, the concentration of each sterol within each lipoprotein was measured to determine the distribution of the sterols in lipoproteins. In these two children, the distribution of individual sterols within each lipoprotein fraction was shown to be the same as the distribution in plasma. We calculated the concentration of each sterol in each lipoprotein fraction in 12 children using the assumption that plasma sterol distribution equaled lipoprotein sterol distribution. These results showed that after dietary cholesterol, l) the cholesterol concentrations in LDL and HDL increased, and 2) there was not a preferential increase of $7 \mathrm{DHC}$ or $8 \mathrm{DHC}$ in either LDL or HDL.

The increases in LDL and HDL cholesterol in these children in response to dietary cholesterol could provide a larger pool of cholesterol available for tissue uptake. It has been shown that ${ }^{125} \mathrm{I}-\mathrm{HDL}_{2}$ from plasma of patients with abetalipoproteinemia was bound, taken up, and degraded by cultured human fibroblasts (37a). This suggests that HDL in addition to LDL can transport cholesterol to tissues. Kinetic studies will be needed to determine whether there is a corresponding increase in LDL and HDL cholesterol uptake by cholesterol-deficient tissues in SLOS.

Only two published studies have reported lipoprotein data in SLOS patients. Pierquin et al. (38) described one severely affected child. This child had low concentrations of total sterols in LDL $(13 \mathrm{mg} / \mathrm{dL})$ and HDL $(8 \mathrm{mg} / \mathrm{dL})$ and a low concentration of apoA-I $(67 \mathrm{mg} / \mathrm{dL})$, the major protein of $\mathrm{HDL}$, as compared with normal ranges. Behulova et al. (39) performed similar measurements in eight children who had SLOS and were not receiving supplemental or dietary cholesterol. Five of the children were severely affected, and three had less severe clinical features. All eight children studied had low concentrations of total sterols in LDL (range: $0-1.18 \mathrm{mM}$ ) and HDL $(0.13-0.84 \mathrm{mM})$ and low concentrations of apoA-I $(<0.12-$ $0.94 \mathrm{~g} / \mathrm{dL}$ ). The concentrations of total sterols in VLDL were normal or above normal, and the concentrations of apoB were normal or borderline low. Neither the effect of dietary cholesterol on lipoproteins nor the distribution of the individual sterols (in lipoprotein fractions or in plasma) was measured in these two studies.
The effect of dietary cholesterol on plasma sterols was similar to our previous report (19). After 6-19 mo of dietary cholesterol with egg yolk (in most cases), the mean plasma cholesterol in children with SLOS significantly increased when compared with the mean concentration at baseline. The increase in cholesterol $(57 \%, n=16)$ found in the current study was similar to the increase in cholesterol $(55 \%, n=7)$ after 1-3 mo of dietary cholesterol in our earlier study (19). These percentage increases were greater than those increases seen in adults who were given high-cholesterol diets (40). After dietary cholesterol, plasma cholesterol rose to above the fifth percentile in four children of the current study, $3.18 \mathrm{mM}$ for normal children aged 5-9 y (29). Although 10 children showed a decrease in plasma 7DHC (range: 8-77\%), six children had an increase or no change. After dietary cholesterol, the lowest concentration of 7DHC in the SLOS children, $0.04 \mathrm{mM}$, was still higher than normal, $0.00026 \mathrm{mM}$ (41). The bioavailability of egg yolk cholesterol versus crystalline cholesterol has not been reported recently. We chose to use egg yolk as the source of cholesterol in most subjects because there is some evidence that it is more effective in raising plasma cholesterol concentrations. In normal adults, dietary egg yolk increased plasma cholesterol concentrations more readily than crystalline cholesterol supplementation (69 versus $19 \mathrm{mg} / \mathrm{dL}$ ), even though the subjects consumed lower amounts of cholesterol in the form of dietary egg yolks $(475-1425 \mathrm{mg} / \mathrm{d})$ than the amounts consumed as cholesterol in the crystalline form (1200-3600 $\mathrm{mg} / \mathrm{d})$ (42). In this present study, the increases in plasma concentrations were similar in both groups. However, the number of children is too small to determine whether the source of cholesterol made a difference in the plasma sterol response. The absorption of cholesterol from the intestine is complex (43) and may be dependent on many factors, including emulsification, micelle formation (44), and cholesterol transporters $(45,46)$.

Dietary cholesterol presumably would lower plasma 7DHC and 8DHC in SLOS by inhibiting hepatic hydroxymethyl glutaryl (HMG) CoA reductase through feedback inhibition of this rate-limiting enzyme. We have shown that dietary cholesterol (for 2 mo or 2 y) decreased HMG CoA reductase activity as measured by the amount of mevalonate in 24-h urine samples. Only after $2 \mathrm{y}$, however, was there a decrease in plasma 7DHC $(n=4)(19)$. These results and the wide range of responses of plasma 7DHC in our current study reflect the complex regulation of the cholesterol biosynthetic pathway.

\section{CONCLUSION}

This is the first report of the effect of dietary cholesterol on sterols in lipoproteins in children with SLOS and of the distribution of cholesterol, 7DHC, and 8DHC in lipoproteins. Increase of total sterols in plasma in response to dietary cholesterol was paralleled by increases of total sterols in LDL and HDL. Calculated concentrations of cholesterol in LDL and HDL also increased. This bodes well for potential therapy of SLOS, because the increased LDL and HDL cholesterol provides a larger pool of cholesterol for tissue uptake. The plasma 7DHC concentrations did not return to normal in the current 
study. Although dietary cholesterol inhibits HMG CoA reductase in SLOS (19), further inhibition, perhaps by statin drugs, may be necessary to normalize the 7DHC.

Acknowledgments. We thank Gary Sexton, Ph.D., for assistance with statistical analysis and Pam Smith and Carol Marsh for lipoprotein separation. We thank the children and families for participation in the study and the staff of the Oregon Health \& Science University General Clinical Research Center. We thank Sandra Banta-Wright, R.N., M.S.N., N.N.P., Daniel Marks, M.D., and numerous other health care providers who assisted in the care of these children. We thank the many health care providers who kindly referred these children to us.

\section{REFERENCES}

1. Smith DW, Lemli L, Opitz JM 1964 A newly recognized syndrome of multiple congenital anomalies. J Pediatr 64:210-217

2. Irons M, Elias ER, Salen G, Tint GS, Batta AK 1993 Defective cholesterol biosynthesis in Smith-Lemli-Opitz syndrome. Lancet 341:1414

3. Tint GS, Irons M, Elias ER, Batta AK, Frieden R, Chen TS, Salen G 1994 Defective cholesterol biosynthesis associated with the Smith-Lemli-Opitz syndrome. N Engl J Med 330:107-113

4. Shefer S, Salen G, Batta AK, Honda A, Tint GS, Irons M, Elias ER, Chen TC, Holick MF 1995 Markedly inhibited 7-dehydrocholesterol-delta 7-reductase activity in liver microsomes from Smith-Lemli-Opitz homozygotes. J Clin Invest 96:17791785

5. Wassif CA, Maslen C, Kachilele-Linjewile S, Lin D, Linck LM, Connor WE, Steiner RD, Porter FD 1998 Mutations in the human sterol delta7-reductase gene at 11q12-13 cause Smith-Lemli-Opitz syndrome. Am J Hum Genet 63:55-62

6. Waterham HR, Wijburg FA, Hennekam RC, Vreken P, Poll-The BT, Dorland L, Duran M, Jira PE, Smeitink JA, Wevers RA, Wanders RJ 1998 Smith-Lemli-Opitz syndrome is caused by mutations in the 7-dehydrocholesterol reductase gene. Am J Hum Genet 63:329-338

7. Fitzky BU, Witsch-Baumgartner M, Erdel M, Lee JN, Paik YK, Glossmann H, Utermann G, Moebius FF 1998 Mutations in the Delta7-sterol reductase gene in patients with the Smith-Lemli-Opitz syndrome. Proc Natl Acad Sci USA 95:81818186

8. Waterham HR, Wanders RJ 2000 Biochemical and genetic aspects of 7-dehydrocholesterol reductase and Smith-Lemli-Opitz syndrome. Biochim Biophys Acta 1529:340-356

9. Nowaczyk MJ, Nakamura LM, Waye JS 2001 DHCR7 and Smith-Lemli-Opitz syndrome. Clin Invest Med 24:311-317

10. Battaile KP, Steiner RD 2000 Smith-Lemli-Opitz syndrome: the first malformation syndrome associated with defective cholesterol synthesis. Mol Genet Metab $71: 154-162$

11. Irons M, Elias ER, Tint GS, Salen G, Frieden R, Buie TM, Ampola M 1994 Abnormal cholesterol metabolism in the Smith-Lemli-Opitz syndrome: report of clinical and biochemical findings in four patients and treatment in one patient. Am J Med Genet 50:347-352

12. Nwokoro NA, Hyde B, Mulvihill JJ 1994 Smith-Lemli-Opitz syndrome: biochemical before clinical diagnosis; early dietary management. Am J Med Genet 50:375376

13. Ullrich K, Koch HG, Meschede D, Flotmann U, Seedorf U 1996 Smith-Lemli-Opitz syndrome: treatment with cholesterol and bile acids. Neuropediatrics 27:111-112

14. van Rooij A, Nijenhuis AA, Wijburg FA, Schutgens RB 1997 Highly increased CSF concentrations of cholesterol precursors in Smith-Lemli-Opitz syndrome. J Inherit Metab Dis 20:578-580

15. Nwokoro NA, Mulvihill JJ 1997 Cholesterol and bile acid replacement therapy in children and adults with Smith-Lemli-Opitz (SLO/RSH) syndrome. Am J Med Genet 68:315-321

16. Irons M, Elias ER, Abuelo D, Bull MJ, Greene CL, Johnson VP, Keppen L, Schanen C, Tint GS, Salen G 1997 Treatment of Smith-Lemli-Opitz syndrome: results of a multicenter trial. Am J Med Genet 68:311-314

17. Elias ER, Irons MB, Hurley AD, Tint GS, Salen G 1997 Clinical effects of cholesterol supplementation in six patients with the Smith-Lemli-Opitz syndrome (SLOS). Am J Med Genet 68:305-310

18. Linck LM, Lin DS, Flavell D, Connor WE, Steiner RD 2000 Cholesterol supplementation with egg yolk increases plasma cholesterol and decreases plasma 7-dehydrocholesterol in Smith-Lemli-Opitz syndrome. Am J Med Genet 93:360-365

19. Pappu AS, Steiner RD, Connor SL, Flavell DP, Lin DS, Hatcher L, Illingworth DR, Connor WE 2002 Feedback inhibition of the cholesterol biosynthetic pathway in patients with Smith-Lemli-Opitz syndrome as demonstrated by urinary mevalonate excretion. J Lipid Res 43:1661-1669
20. Steiner RD, Linck LM, Flavell DP, Lin DS, Connor WE 2000 Sterol balance in the Smith-Lemli-Opitz syndrome. Reduction in whole body cholesterol synthesis and normal bile acid production. J Lipid Res 41:1437-1447

21. Linck LM, Hayflick SJ, Lin DS, Battaile KP, Ginat S, Burlingame T, Gibson KM, Honda M, Honda A, Salen G, Tint GS, Connor WE, Steiner RD 2000 Fetal demise with Smith-Lemli-Opitz syndrome confirmed by tissue sterol analysis and the absence of measurable 7-dehydrocholesterol Delta(7)-reductase activity in chorionic villi. Prenat Diagn 20:238-240

22. Krakowiak PA, Nwokoro NA, Wassif CA, Battaile KP, Nowaczyk MJ, Connor WE, Maslen C, Steiner RD, Porter FD 2000 Mutation analysis and description of sixteen RSH/Smith-Lemli-Opitz syndrome patients: polymerase chain reaction-based assays to simplify genotyping. Am J Med Genet 94:214-227

23. Martin A, Koenig K, Scahill L, Tierney E, Porter FD, Nwokoro NA 2001 SmithLemli-Opitz syndrome. J Am Acad Child Adolesc Psychiatry 40:506-507

24. Lipid Research Clinics Program 1982 Manual of Laboratory Operations, Lipid and Lipoprotein Analysis, 2nd Ed. Department of Health and Human Services (NIH), Bethesda

25. Wiebe DA, Bernert JT Jr 1984 Influence of incomplete cholesteryl ester hydrolysis on enzymic measurements of cholesterol. Clin Chem 30:352-356

26. Jira PE, de Jong JG, Janssen-Zijlstra FS, Wendel U, Wevers RA 1997 Pitfalls in measuring plasma cholesterol in the Smith-Lemli-Opitz syndrome. Clin Chem 43:129-133

27. Tsukamoto K, Watanabe T, Matsushima T, Kinoshita M, Kato H, Hashimoto Y, Kurokawa K, Teramoto T 1993 Determination by PCR-RFLP of apo E genotype in a Japanese population. J Lab Clin Med 121:598-602

28. Raymond TL, Connor WE, Lin DS, Warner S, Fry MM, Connor SL 1977 The interaction of dietary fibers and cholesterol upon the plasma lipids and lipoproteins, sterol balance, and bowel function in human subjects. J Clin Invest 60:1429-1437

29. Kwiterovich PO Jr 1991 Plasma lipid and lipoprotein levels in childhood. Ann NY Acad Sci 623:90-107

30. Utermann G, Kindermann I, Kaffarnik H, Steinmetz A 1984 Apolipoprotein E phenotypes and hyperlipidemia. Hum Genet 65:232-236

31. Ikonen E 2001 Roles of lipid rafts in membrane transport. Curr Opin Cell Biol 13:470-477

32. Kabouridis PS, Janzen J, Magee AL, Ley SC 2000 Cholesterol depletion disrupts lipid rafts and modulates the activity of multiple signaling pathways in $\mathrm{T}$ lymphocytes. Eur J Immunol 30:954-963

33. Mauch DH, Nagler K, Schumacher S, Goritz C, Muller EC, Otto A, Pfrieger FW 2001 CNS synaptogenesis promoted by glia-derived cholesterol. Science 294:13541357

34. Kelley RI, Hennekam RC 2000 The Smith-Lemli-Opitz syndrome. J Med Genet 37:321-335

35. Xu G, Servatius RJ, Shefer S, Tint GS, O’Brien WT, Batta AK, Salen G 1998 Relationship between abnormal cholesterol synthesis and retarded learning in rats. Metabolism 47:878-882

36. Roux C, Wolf C, Mulliez N, Gaoua W, Cormier V, Chevy F, Citadelle D 2000 Role of cholesterol in embryonic development. Am J Clin Nutr 71:1270S-1279S

37. Ketomaki A, Gylling H, Siimes MA, Vuorio A, Miettinen TA 2003 Squalene and noncholesterol sterols in serum and lipoproteins of children with and without familial hypercholesterolemia. Pediatr Res 53:648-653

37a. Illingworth DR, Alam NA, Sundberg EE, Hagemenas FC, Layman DL 1983 Regulation of low density lipoprotein receptors by plasma lipoproteins from patients with abetalipoproteineinemia. Proc Natl Acad Sci USA 80:3475-3479

38. Pierquin G, Peeters P, Roels F, Vamos E, Brucher JM, Tint GS, Honda A, Van Regemorter N 1995 Severe Smith-Lemli-Opitz syndrome with prolonged survival and lipid abnormalities. Am J Med Genet 56:276-280

39. Behulova D, Bzduch V, Skodova J, Dello Russo A, Corso G, Ponec J, Kasanicka A 2000 Serum lipids and apolipoproteins in children with the Smith-Lemli-Opitz syndrome. J Inherit Metab Dis 23:413-415

40. Connor WE, Connor SL 2002 Dietary cholesterol and coronary heart disease. Curr Atheroscler Rep 4:425-432

41. Cunniff C, Kratz LE, Moser A, Natowicz MR, Kelley RI 1997 Clinical and biochemical spectrum of patients with RSH/Smith-Lemli-Opitz syndrome and abnormal cholesterol metabolism. Am J Med Genet 68:263-269

42. Connor WE, Hodges RE, Bleiler RE 1961 The serum lipids in men receiving high cholesterol and cholesterol-free diets. J Clin Invest 40:894-901

43. Ros E 2000 Intestinal absorption of triglyceride and cholesterol. Dietary and pharmacological inhibition to reduce cardiovascular risk. Atherosclerosis 151:357379

44. Yao L, Heubi JE, Buckley DD, Fierra H, Setchell KD, Granholm NA, Tso P, Hui DY, Woollett LA 2002 Separation of micelles and vesicles within lumenal aspirates from healthy humans: solubilization of cholesterol after a meal. J Lipid Res 43:654-660

45. Altmann SW, Davis HR Jr, Zhu LJ, Yao X, Hoos LM, Tetzloff G, Iyer SP, Maguire M, Golovko A, Zeng M, Wang L, Murgolo N, Graziano MP 2004 Niemann-Pick C1 Like 1 protein is critical for intestinal cholesterol absorption. Science 303:12011204

46. Plat J, Mensink RP 2002 Increased intestinal ABCA1 expression contributes to the decrease in cholesterol absorption after plant stanol consumption. FASEB J 16:1248-1253 